Prozess und löste 1963 mit der Veröffentlichung ihres Buches, ${ }^{439}$ in dem sie im Zusammenhang mit der nationalsozialistischen Judenvernichtung zum einen das Verhalten der Judenräte kritisierte und zum anderen mit Blick auf Adolf Eichmann die These von der Banalität des Bösen aufwarf, eine heftige politische und wissenschaftliche Kontroverse aus. ${ }^{440}$

Arendt nahm 1967 eine Professur an der New School for Social Research an und begann mit den Vorarbeiten für ihr philosophisches Buch The Life of the Mind. ${ }^{441}$ Nachdem sie ihre beiden wichtigsten Freunde verloren hatte - 1969 starb Karl Jaspers und 1970 Heinrich Blücher -, starb Arendt am 4. Dezember 1975 im Alter von 69 Jahren nach einem Herzinfarkt in ihrer Wohnung in New York.

\title{
4.9 Peter de Mendelssohn
}

Der britisch-deutsche Journalist und Schriftsteller Peter de Mendelssohn gehörte nach der nationalsozialistischen Machteroberung zu den "Emigranten der ersten Stunde« (Hilde Spiel). Er wurde am 1. Juni 1908 in München als Sohn eines Goldschmieds geboren. Die Mutter stammte aus Argentinien. Sein »einziger jüdischer Großvater« war ein Gelehrter von Rang und mit dem renommierten Historiker Theodor Mommsen befreundet. ${ }^{442}$ Nach dem Abitur begann er, in der Redaktion des Berliner Tageblattes mitzuarbeiten, und konnte sich mit verschiedenen literarischen Veröffentlichungen einen Namen machen. ${ }^{443}$ Am 1. April 1933 wurde de Mendelssohn mit seinem Vater in Berlin Augenzeuge der antisemitischen Boykottaktion durch die NSDAP und verließ kurz darauf - »viele unserer Freunde und Bekannten hatten sich (bereits) Mord und Totschlag und anderer Drangsalierung durch Flucht über die Grenze entzogen ${ }^{444}$ - Deutschland in Richtung »Pariser Exil« und ging über Wien 1936 noch vor dem »Anschluss Österreichs« an Deutschland nach London. Dort heiratete er die jüdisch-österreichische Schriftstellerin Hilde Spiel ${ }^{445}$ und erhielt 1941 die britische Staatsbürgerschaft. Diese

439 Eichmann in Jerusalem: A Report on the Banality of Evil, New York 1963 (dt. Ausg.: Eichmann in Jerusalem. Ein Bericht von der Banalität des Bösen, München 1964).

440 Siehe hierzu F. A. Krummacher (Hg.), Die Kontroverse. Hannah Arendt, Eichmann und die Juden, München 1964.

441 Hannah Arendt, The Life of the Mind, 2 Bde., New York 1978 (dt. Ausg.: Vom Leben des Geistes, Bd. 1: Das Denken, Bd. 2: Das Wollen, München 1979). Vgl. hierzu sowie primär zu den philosophischen Studien Arendts - mit Ausnahme von Eichmann in Jerusalem - die in den Vereinigten Staaten nach ihrer Rückkehr aus Europa 1950 angefertigten Serien von Aufzeichnungen: Hannah Arendt, Denktagebuch. 1950-1973, 2 Bde., München 2002.

442 Peter de Mendelssohn, Der Geist in der Despotie. Versuche über die Möglichkeiten des Intellektuellen in der totalitären Gesellschaft. Mit einem Vorwort von Karl Jaspers, Berlin-Grunewald 1953, S. 9.

443 Siehe hierzu Hilde Spiel, Der Erzähler Peter de Mendelssohn, in: Peter de Mendelssohn, Die Kathedrale. Ein Sommernachtmahr. Mit einem Nachwort von Hilde Spiel, Berlin 1988, S. 237-264.

444 De Mendelssohn, Der Geist in der Despotie, S. 9.

445 Hilde Spiel wurde 1911 in Wien geboren (gestorben 1990 in Wien) und wuchs im Milieu des assimilierten jüdischen Bürgertums auf. Sie emigrierte 1936 nach London. Dort arbeitete sie für verschiedene internationale Zeitungen und Zeitschriften und setzte ihre schriftstellerische Tätigkeit fort. Nach dem Krieg kehrte sie mit de Mendelssohn nach Berlin zurück und war dort als Theaterkritikerin aktiv und schrieb u. a. in der Die Neue Zeitung. Spiel zählte wie ihr Mann zu den Autoren der Zeitschrift Der Monat. Sie veröffentlichte dort insbesondere Artikel über die englische Literatur. Siehe zu Spiel 
Jahre waren für de Mendelssohn auch durch die Ungewissheit geprägt, wie es seiner Mutter und seinem jüngsten Bruder in Deutschland erging, da beide zwar »technisch kaum gefährdet « waren, gleichwohl Diffamierungen ausgesetzt waren. ${ }^{446}$ In England machten de Mendelssohn und Spiel unter anderem Bekanntschaft mit Koestler und Aron.

1944 trat de Mendelssohn in die britisch-amerikanische Abteilung Psychological Warfare Division der Alliierten Armee ein und wurde mit dem Auftrag betreut, deutsche Journalisten für die ersten amerikanisch lizenzierten Zeitungen zu suchen. ${ }^{447}$ Er war maßgeblich an der Begründung des Berliner Tagesspiegel, des Telegraf und der Welt beteiligt. Für die britische Besatzungsmacht besuchte er den Nürnberger Hauptkriegsverbrecherprozess und veröffentlichte in diesem Zusammenhang das Buch Die Nürnberger Dokumente. Studien zur deutschen Kriegspolitik 1937-1945, mit dem er in erster Linie den Zweck verfolgte, »sich mit Hitlers Technik der Kriegsanzettelung zu befassen, der politischen und militärischen Planung, wie sie zum Krieg und in den Krieg hineinführte, in ihren verschiedenen Phasen soweit wie möglich zu folgen und sich ein Bild zu verschaffen von der Gesamtkonzeption, die diese Planung beherrschte ${ }^{448}$.

$\mathrm{Ab} 1950$ war er unter anderem für die von der amerikanischen Besatzungsmacht in Deutschland herausgegebene Tageszeitung Neue Zeitung als Korrespondent in London tätig. Unter den zahlreichen in deutscher und englischer Sprache verfassten, vorwiegend literarischen Büchern ist vor allem seine Thomas-Mann-Biografie zu nennen. ${ }^{449}$ De Mendelssohn erhielt im April 1975 den Thomas-Mann-Preis der Hansestadt Lübeck. Von 1975 bis zu seinem Tode war er Präsident der Deutschen Akademie für Sprache und Dichtung. Er war seit 1970 Mitglied des P.E.N.-Zentrums der Bundesrepublik und erhielt mehrere Auszeichnungen: z. B. 1976 den Bayerischen Verdienstorden sowie 1979 das Große Bundesverdienstkreuz. De Mendelssohn starb 74-jährig am 10. August 1982 in München.

Im Monat schrieb de Mendelssohn neben einem Beitrag über die BBC einerseits über soziale und politische Themen in Bezug auf England ${ }^{450}$ und andererseits $\mathrm{zu}$ deutschlandspezifischen Themenkomplexen. Neben dem Wiederaufkommen des Nationalismus im Nachkriegsdeutschland ${ }^{451}$ beschäftigte er sich mit der sogenannten

die beiden autobiografischen Bände: Die hellen und die finsteren Zeiten. Erinnerungen 1911-1946, München 1989; Welche Welt ist meine Welt? Erinnerungen 1946-1989, Frankfurt a. M./Wien 1991.

446 Spiel, Die hellen und die finsteren Zeiten, S. 117

447 Schivelbusch, Vor dem Vorhang, S. 244. Vgl. hierzu Peter de Mendelssohn, Zeitungsstadt Berlin, Menschen und Mächte in der Geschichte der deutschen Presse, Berlin 1959.

448 Peter de Mendelssohn, Die Nürnberger Dokumente. Studien zur deutschen Kriegspolitik 1937-45, Hamburg 1947, S. 15 f.

449 Ders., Der Zauberer. Das Leben des deutschen Schriftstellers Thomas Mann, München 1975.

450 BBC. Die Naturgeschichte eines Rundfunkmonopols, in: Der Monat 3 (1951), H. 36, S. 594-605, sowie 4 (1951), H. 37, S. 68-84; Vorsichtige Revolution ohne Tränen, in: Der Monat 4 (1952), H. 43, S. $83-87$ (Rezension); Brief aus London: Die Herrschaft der Wenigen, in: Der Monat 4 (1952), H. 48, S. 581-588; Brief aus London: Unbehagen in Westminister, in: Der Monat 5 (1953), H. 56, S. 125-134. Vgl. hierzu auch Peter de Mendelssohn, Inselschicksal England. Schrittsteine der Geschichte, München 1965.

451 Im Zwielicht der Begriffe, in: Der Monat 1 (1949), H. 8/9, S. 45-49 (hierbei handelte es sich um einen Beitrag im Rahmen des vom Monat organisierten Symposiums Erwacht Deutschland schon wieder? Derneue deutsche Nationalismus und seine Gefahren). Siehe die Beiträge von Richard H. S. Crossmann, Raymond Aron, Dolf Sternberger, Richard Löwenthal u. a. im selben Heft. 
Memoirenliteratur und den Intellektuellen. In seinem Beitrag Die verhinderten Hochverräter problematisierte er nicht zuletzt das vom ehemaligen Mitarbeiter des Auswärtigen Amtes in der Zeit des Naziregimes, Ernst von Weizsäcker, verfasste Buch Erinnerungen. ${ }^{452}$

De Mendelssohn beleuchtete intensiv das Verhältnis von Intellektuellen zum NSSystem. Sein Beitrag Gegenstrahlungen, in dem er sich kritisch mit Ernst Jünger auseinandersetzte, ${ }^{453}$ mündete inhaltlich in das Kapitel »Über die Linie des Geringsten Widerstandes. Versuch über Ernst Jünger « seines 1953 erschienenen Buches Der Geist in der Despotie. Versuche über die moralischen Möglichkeiten des Intellektuellen in der totalitären Gesellschaft ${ }^{454}$. Hierbei ging er der Frage der Rolle des Intellektuellen, seinen moralischen Möglichkeiten und moralischen Verpflichtungen in einer »totalitären Despotie« nach, und zwar anhand von Knut Hamsun, Jean Giono, Gottfried Benn ${ }^{455}$ und dem bereits genannten Ernst Jünger. Das Kapitel über Hamsun erschien in einer stark gekürzten Fassung im Monat. ${ }^{456}$ Auf dem Berliner »Kongreß für kulturelle Freiheit« im Juni 1950 betonte de Mendelssohn in seinem Vortrag Die Versuchung des Intellektuellen die »magische Anziehungskraft« geschlossener, totalitärer Denksysteme auf Intellektuelle. $^{457}$

\subsection{Herbert Lüthy}

Mit knapp 70 Veröffentlichungen zählte der Historiker, Essayist und freie Journalist Herbert Lüthy zu den zweifelsohne populärsten und einflussreichsten Autoren der Zeitschrift Der Monat. Parallel veröffentlichte er zahlreiche Beiträge in der französischen »Partnerzeitschrift« Preuves, sodass er zu einem »der wichtigsten Verbindungsglieder dieses europäischen Zeitschriftennetzwerkes « zählte. ${ }^{458}$

Lüthy wurde in Basel als Sohn eines Missionars am 15. Januar 1918 geboren und besuchte bis 1938 die Schulen in Glarus und St. Gallen. Während des Zweiten Weltkrieges studierte Lüthy in Zürich Geschichte, französische Sprache und Literatur und schloss das Studium 1943 mit einer Dissertation zum Thema Die Tätigkeit der Schweizer Kaufleute und Gewerbetreibenden in Frankreich unter Ludwig XIV. und der Regentschaft ab. ${ }^{459}$ Nach Kriegsende lebte Lüthy bis 1958 in Paris und arbeitete in diesen Jahren nicht nur

452 Die Verhinderten Hochverräter. Wege und Irrwege neuerer deutscher Memoirenliteratur, in: Der Monat 3 (1951), H. 29, S. 495-509 (Sammelrezension). Auf diesen Rezensionsaufsatz gehe ich in Kap. IV.1.7 ausführlich ein.

453 Gegenstrahlungen. Ein Tagebuch zu Ernst ]üngers Tagebuch, in: Der Monat 2 (1949), H. 14, S. 149-174 (Rezension).

454 Der Geist in der Despotie. Versuche über die moralischen Möglichkeiten des Intellektuellen in der totalitären Cesellschaft; siehe hierzu Bondy, Rebellen als Musterschüler.

455 Auf meine Frage, warum der Beitrag über Knut Hamsun und nicht der über Gottfried Benn im Monat veröffentlicht wurde, obwohl dieser in der Zeitschrift angekündigt wurde, sagte der Herausgeber Lasky in einem Gespräch mit dem Verfasser im November 2001 in Berlin, dass der Redaktion dieser Beitrag »politisch zu brisant« erschien.

456 Knut Hamsun. Erleuchtung und Verblendung des Zerrissenen, in: Der Monat 5 (1953), H. 55, S. 50-70.

457 Die Versuchung des Intellektuellen, in: Der Monat 2 (1950), H. 22/23, S. 384-386.

458 So die Einschätzung von François Bondy (zit. n. Ackermann, Sündenfall der Intellektuellen, S. 81).

459 So Lüthy in einem Gespräch mit dem Verfasser im Juli 2001 in Basel. 